\title{
Evolutionary modeling in economics: recent history and immediate prospects
}

Citation for published version (APA):

Silverberg, G. P. (1997). Evolutionary modeling in economics: recent history and immediate prospects. MERIT, Maastricht Economic Research Institute on Innovation and Technology. MERIT Research Memoranda No. 008 https://doi.org/10.26481/umamer.1997008

Document status and date:

Published: 01/01/1997

DOI:

10.26481/umamer.1997008

Document Version:

Publisher's PDF, also known as Version of record

\section{Please check the document version of this publication:}

- A submitted manuscript is the version of the article upon submission and before peer-review. There can be important differences between the submitted version and the official published version of record.

People interested in the research are advised to contact the author for the final version of the publication, or visit the DOI to the publisher's website.

- The final author version and the galley proof are versions of the publication after peer review.

- The final published version features the final layout of the paper including the volume, issue and page numbers.

Link to publication

\footnotetext{
General rights rights.

- You may freely distribute the URL identifying the publication in the public portal. please follow below link for the End User Agreement:

www.umlib.nl/taverne-license

Take down policy

If you believe that this document breaches copyright please contact us at:

repository@maastrichtuniversity.nl

providing details and we will investigate your claim.
}

Copyright and moral rights for the publications made accessible in the public portal are retained by the authors and/or other copyright owners and it is a condition of accessing publications that users recognise and abide by the legal requirements associated with these

- Users may download and print one copy of any publication from the public portal for the purpose of private study or research.

- You may not further distribute the material or use it for any profit-making activity or commercial gain

If the publication is distributed under the terms of Article $25 \mathrm{fa}$ of the Dutch Copyright Act, indicated by the "Taverne" license above, 
Evolutionary Modeling in Economics: Recent History and Immediate Prospects

\author{
Gerald Silverberg
}

MERIT

University of Maastricht

P.O. Box 616

NL-6200 MD Maastricht

The Netherlands

Email gerald.silverberg@ merit.unimaas.nl

July 1997 first revision

Prepared for the workshop on "Evolutionary Economics as a Scientific Research Programme", Stockholm, May 26-27, 1997. 


\section{Introduction: the why and what of evolutionary modelling}

Evolutionary arguments in economics, as in biology, originally took purely verbal forms, and it was only with considerable delay, as in biology as well, that more formal (i.e., more mathematical or algorithmically based) arguments and models were advanced. On the one hand we can see this as a natural process in the development of science. On the other it is somewhat surprising, since the mathematical tools that began to be employed starting in the 1960s had been developed by mathematical biologists in the 1920s and 30s and were widely known (the computer-based ones, of course, had to wait until the more widespread availability of computers, and in particular, of computer literacy, in the 1960s and 70s).

One reason for this delay was the slow recognition of the appropriateness of evolutionary arguments in economics at all [this is dealt with in a number of other contributions to this volume]. There were at least two streams of thought at work here. One, going back to Alchian (1951), argued in evolutionary terms to justify leaps of faith in the neoclassical framework by relaxing the strong assumptions of rationality traditionally employed to justify equilibria. The other, associated with the Austrian school (cf. for example Witt 1994), invoked evolutionary or selforganizational arguments of an almost mystical, nonformalizable sort to separate itself from that same neoclassical mainstream. Paradoxically, they both left unchallenged the central neoclassical result, viz., that the unfettered market left to itself would evolve to an optimal state. But whereas one felt compelled to draw on evolutionary mechanisms to overcome formal shortcomings of the standard argument, the other rejected both this argument in principle as applicable to the problem and implicitly denied the applicability of formal methods at all.

If we view an evolutionary approach, in contrast to the Austrian school, as compatible with formal methods, however, it is interesting to follow the aspirations of researchers over time in employing them. First, as a confirmation of nonformal intuitions, particularly regarding the usefulness of evolutionary arguments in shoring up (neo)classical results with less restrictive assumptions. Second, as an exercise in its own right in mathematical methods in economics, an enterprise that had acquired increasing weight in the postwar academic economics community. And thirdly, as an approach capable of generating new economic insights, or bolstering alternative ones, outside of the received tradition. Naturally these 
motives were not always explicit or even mutually exclusive. In the course of the following we will have occasion to review various approaches from the perspective of these motives.

The task of this review is considerably simplified by the appearance of many lucid overviews of the whole topic of evolutionary economics in recent years (Nelson and Winter 1982, Nelson 1995, Saviotti and Metcalfe 1991, Dosi and Nelson 1994, Andersen 1994, Silverberg 1988, Hodgson 1993, Dopfer 1997), as well as more specialized reviews on individual aspects, which will be cited as the need arises. In fact, there is a real danger that the subject is beginning to suffer from an imbalance between reviews and invocations of methodological principles on the one hand and substantive original contributions on the other. Is the paucity of the latter the motivation for the fecundity of the former, to give researchers the appearance of productivity by constantly hashing and rehashing the same fundamental material in lieu of genuinely new results? I advance this as a provocation to the community of evolutionary economists, although, of course, in the following I will attempt to some extent to rebut my own charge.

This cornucopia of reviews makes yet another systematic and detailed discussion of the literature somewhat superfluous. Instead, I will concentrate in the first instance on structuring the basic approaches, and then discuss the accomplishments, limitations, and prospects of the some of the work (perhaps idiosyncratically selected) undertaken along these lines in the last ten years. This paper, in contrast to Silverberg (1988), will concentrate on evolutionary models in a wide sense but will exclude selforganizational models, of which there are also many new examples since 1988, even if few of them represent a radical departure from the earlier approaches. While the distinction is often a fine one, by evolutionary models I understand models presupposing populations of entities in competition with one another for resources, survival or other form of generalized payoff, and not merely interacting through some other nexus such as contagion with no or more circumscribed consequences for the viability of the individual entity. ${ }^{1}$ Thus stratification models such as Durlauf (1996b), market selforganization models such as Weisbuch, Kirman, and Herreiner (1996), and collective dynamics models of imitation and herd behaviour such as Orlean (1995) will not be discussed here, although the formalisms have many points of tangency with

\footnotetext{
${ }^{1}$ Although some formulations of imitation processes can lead to precisely the same evolutionary dynamics discussed in the following (cf. Schlag 1994, Weibull 1995).
} 
evolutionary models in the stricter sense. ${ }^{2}$ When we come to the application of 'evolutionary intelligence' methods (such as genetic algorithms and classifier systems) to social interaction models the distinction will prove harder to maintain.

II. One Side of Evolutionary Models: Selection (Deterministic and Single Equilibrium)

Fisher's Fundamental Theorem as Mathematical Foundation and Replicator Dynamics

Formalization of evolutionary thinking in biology in dynamic terms began with Fisher (1930), who introduced what are now called replicator equations ${ }^{3}$ to capture Darwin's notion of the survival of the fittest. If we consider a population to be composed of $n$ distinct competing "varieties" with associated, possibly frequency-dependent fitnesses $f_{i}(\boldsymbol{x})$, where $\boldsymbol{x}$ is the vector of relative frequencies of the varieties $\left(x_{1}, x_{2}, \ldots, x_{n}\right)$, then their evolution might be described by the following equations:

$$
\dot{x}_{i}=x_{i}\left(f_{i}(\boldsymbol{x})-\bar{f}(\boldsymbol{x})\right), i=1, n, \text { with } \bar{f}(\boldsymbol{x})=\sum_{i=1}^{n} x_{i} f_{i}(\boldsymbol{x}) .
$$

The intuition is simple: varieties with above-average fitness will expand in relative importance, those with below-average fitness will contract, while the average fitness $\bar{f}(\boldsymbol{x})$ in turn changes with the relative population weights. If the fitness functions $f_{i}$ are simple constants, then it can be shown that the variety with the highest fitness will displace all the others and that average fitness will increase monotonically until uniformity is achieved according to

$$
\frac{d \bar{f}}{d t}=\operatorname{var}(f) \geq 0,
$$

where $\operatorname{var}(f)$ is the frequency-weighted variance of population fitness. Thus average fitness is dynamically maximized by the evolutionary process (mathematically, it is referred to as a

${ }^{2}$ Deriving in the main from statistical mechanical approaches, they lie well within the social science modeling tradition established by Weidlich and Haag 1983 (see also Weidlich and Braun 1992) and discussed in my previous survey.

${ }^{3}$ See Sigmund (1986) and Hofbauer and Sigmund (1988, pp.145-6) for a discussion of their basic form and various applications. 
Lyapunov function). This is known as Fisher's Fundamental Theorem of Natural Selection, but it should be noted that it is only valid for constant fitness functions. In the event of frequency-dependent selection, where fitness depends on population shares, including a variety's own share, and increasing and decreasing 'returns' may intermingle, multiple equilibria are possible and no quantity is a priori necessarily being maximized (see Ebeling and Feistel 1982 for an extensive discussion of maximal principles). The replicator equation only describes the relative share dynamics and thus takes place on the unit simplex $S^{n}$ (where $\sum_{i=1}^{n} x_{i}=1$ ), an $n-1$ dimensional space. To derive the absolute populations it is necessary to introduce an additional equation for the total population level. An alternative description due to Lotka and Volterra is based on growth equations for the population levels $y_{i}$ (with the frequently used log-linear version on the right hand side):

$$
\dot{y}_{i}=g_{i}(\boldsymbol{y})=r_{i} y_{i}+\sum_{j=1}^{n} a_{i j} y_{i} y_{j}
$$

A theorem due to Hofbauer asserts that Lotka-Volterra and replicator systems are equivalent (see Hofbauer and Sigmund 1988, p. 135).

Most evolutionary economics models to a considerable extent consist of giving the functions $f_{i}$ or $g_{i}$ economic meaning in terms of market competition or differential profit rate driven selection mechanisms. The former usually defines a variable representing product competitiveness, which may be a combination of price, quality, deliver delay, advertising and other variables (for examples see Silverberg, Dosi and Orsenigo 1988 or Kwasnicki and Kwasnicka 1992). The latter assumes that product quality and price are homogeneous between producers (or subject to fast equilibrating dynamics compared to the evolutionary processes of interest) but unit costs of production differ, so that firms realize differential profit rates. If their growth rates are related to profits, as seems reasonable, then their market shares or production levels (corresponding to $x_{i}$ and $y_{i}$ in the biological models) can be described by replicator or Lotka-Volterra equations, respectively.

\section{(Non)invadability Criteria}

Complementary to the attempt to formulate an evolutionary dynamics has been the search for 
some evolutionary notion of equilibrium. Dynamical systems, of course, have a natural notion of (point) equilibrium based on Lyapunov's asymptotic stability concept: that point to which the system converges from some set of initial conditions if one waits long enough. In some simple evolutionary contexts this suffices to derive meaningful selection criteria (in ecological predator/prey models for example Allen 1975, 1976; in a related model of technology selection Silverberg 1984). Such criteria have assumed most prominence in evolutionary game theory, where the evolutionary process has been modeled as expected (i.e., population share weighted) payoffs to pairwise interactions between individuals from the same or distinct populations. ${ }^{4}$ The original static equilibrium concept is evolutionarily stable state (ESS), which defines a population state to be stable if a mutant receives a smaller payoff than a representative of the original population playing against the original population augmented by a small number of these mutants. This ensures that the mutant, if introduced in sufficiently small quantities, cannot spread. An ESS turns out to be a refinement of the game theorist's favourite notion of Nash equilibrium. In the meantime a number of additional concepts of evolutionary stability have been introduced, as well as juxtaposed with dynamical formulations, for example, using replicator dynamics with the game payoffs as dynamical fitness functions.

\section{Diffusion of Technology Models}

The identification of technologies with varieties leads to a class of models dealing with technology diffusion. The first generation of such models essentially relied on fairly straightforward applications of Fisher's work (see e.g. Metcalfe 1988), although the authors may not have been aware of it at the time. The subject becomes more interesting when the fitnesses themselves depend on population proportions rather than being constants, since Fisher's theorem then breaks down and we enter into the domain of (deterministic) path dependence and possible lock-in to an inferior technology, in contrast to the Panglossian

\footnotetext{
${ }^{4}$ The best survey of the foundational work is Maynard Smith (1982). Recently a number of superb surveys of this burgeoning field (at least from the mathematical point of view) have appeared: Hammerstein and Selten (1994), Kandori (1996), Vega-Redondo (1996), Weibull (1995). For this reason I will refrain from discussing evolutionary game theory in detail and only flag some particular implications for more applied evolutionary modeling.
} 
implications of the standard case. Amable (1992), Englmann (1988) and Metcalfe (1994), among others, have focused explicitly on the implications of increasing returns in this deterministic dynamical setting. However, it is in the stochastic domain that the concept of increasing returns holds the most mathematical interest. Saviotti and Mani (1995) is a further elaboration on the applicability of replicator dynamics and Lotka-Volterra equations, differentiating technologies by locating them in a characteristics space, although appearing more 'formal' than operationalizable as a theoretical framework.

Kwasnicki (1996b) has also adopted the standard replicator dynamics framework to permit econometric estimation of multiple technology competition and forecasting, and applied it to a number of historical cases.

Industry-Level Competition Models with Technological Diffusion

By identifying the firm with the unit of competition instead of the technology, a group of related deterministic nonlinear models has been explored by a number of authors. Technology remains in these models the driving force for change, but it is the characteristic features now of the firms in their implementation of technology and other aspects of their strategic behaviour on markets that determine how competition is realized. All of these models essentially employ replicator dynamics for market shares and define fitness in terms of some notion of economic competitiveness. The latter is primarily a price variable with a wide range of possibilities of augmenting it with such things as delivery delays, product quality measures, advertising, etc. Kwasnicki's work (Kwasnicki and Kwasnicka 1992, Kwasnicki 1996) has gone particularly far in integrating (endogenously determined) product characteristics into a model of a competitive industry, although it remains far from anything that could be specified empirically.

A number of papers have looked at the structural and time series properties resulting from a basic replicator-like diffusion of technologies with a constant stream of new innovations. Picking up on the formulation of Iwai (1984a,b), Henkin and Polterovich (1991) derive a travelling wave structure for the distribution of technologies in technology space. In a closed economy model generalizing Silverberg (1984) to a world with Poisson-generated innovations Silverberg and Lehnert $(1994,1996)$ show that rather than obtaining a unique technology distribution moving in time, the distribution fluctuates in a long-wave manner. As 
opposed to the periodic interpretation of long waves, however, they identify a time-series property they term 'evolutionary chaos' with aspects of low-dimensional chaos and $1 / f^{\alpha}$-noise. Englmann $(1992,1994)$ also explore some macroeconomic implications of this approach to embodied technological change, both exogenously specified and 'endogenous'.

\section{Selection Continued: Stochastic Dynamics}

Master Equation Approaches

The models of the previous paragraph moved from purely deterministic systems to deterministic equations with randomly determined innovation dates. A separate strand of literature has examined selection processes from a completely stochastic perspective, i.e., in which the relative share dynamics are formulated probabilistically. Two main approaches have dominated the literature on technological change in an uneasy coexistence: continuous time Markov processes or Master equations, and discrete time Polya urns. The Master equation approach considers finite discrete state spaces for a fixed population size and posits transitions probabilities per unit time for one element of the population to move from one category to another of the state space, as a function of the present population state. Probability flow accounting leads to a differential equation for the time rate of change of the probability distribution over the states, the Master equation. In practice this distribution can be used in fairly standard ways to make assertions about the limiting distribution on the one hand, and to formulate deterministic dynamic equations for the mean values on the other (see Weidlich and Braun 1992 for examples).

Proceeding from the original work of Jiménez Montaño and Ebeling (1980), Bruckner et al. (1996) demonstrate the added value of a stochastic approach to the innovation diffusion problem. They derive explicit expressions for the probability of extinction of a new technology in the competitive diffusion process and show that, in contrast to the deterministic case, where the superior technology always wins, in a stochastic world it may still fail to diffuse if its economic merit is not sufficiently greater than that of the incumbent or if it is not initially introduced in sufficiently large quantities. The Nelson and Winter model can also be formulated in a Master equation framework. 


\section{Polya Urn Approaches}

The alternative Polya urn approach considers infinitely increasing populations of entities of different classes in which at each step in discrete time one entity is added to the population whose type is determined probabilistically according to an allocation function. The allocation function is a map of the $n$-simplex onto itself (where $n$ is the number of types) assigning to the realized frequencies of types in the existent population the probabilities of adding a new entity of each type. A theorem of Arthur, Ermoliev, and Kaniovski (1984) (see also Arthur 1994 for a compilation of relevant papers on this topic) shows that such a system will converge with probability one to one of the fixed points of the allocation function, and that whether such a fixed point is attracting or repelling can be determined by the asymptotic stability of the difference equation dynamics induced by the allocation function.

The implications of this apparatus for the analysis of so-called path dependence and lock-in to inferior technologies in the meantime are well known, and have been further elaborated upon in particular by Cowan $(1991)^{5}$. It has also been applied to oligopolistic price competition by Dosi and Kaniovski (1994), although here the assumptions strike me as even more artificial than in the better known competing technology case. An easily overlooked assumption distinguishing the Polya urn case from Markov processes is that the population must increase monotonically and unboundedly to obtain these results. This is why Polya urns can lead to nonergodic results and convergent lock-in, while the limiting distributions of Markov processes, even if multimodal, will always allow all accessible states to be revisited in principle if one is prepared to wait long enough and there are no simple absorbing states. Thus the blind application of one or the other methodology is not simply a matter of investigator's modeling predilections but is a real empirical question of how technological or

\footnotetext{
${ }^{5}$ Although recently a backlash with strongly neoclassical tinge has challenged these implications, both in terms of the specific examples cited in the literature, such as the QWERTY typewriter keyboard, and the general applicability of the approach to economic coordination problems (cf. Liebowitz and Margolis 1990, 1994, 1995). While in my opinion many of the examples in the literature are indeed based on a too cursory reading of the historical evidence, the rejection of path dependence in general is simply neoclassical Panglossian taken to an absurd extreme. Unfortunately, much of the evidence will always have to be couched in counterfactual terms (see the chapter by Cowan and Foray in this volume).
} 
other populations evolve over time, and if and how large the populations become ${ }^{6}$.

Noisy Dynamics and Stochastic Evolutionary Stability

The stochastic evolutionary selection literature has been considerably enriched in this decade by the seminal paper of Foster and Young (1990) coming out of evolutionary game dynamics. This has lead to a number of stylized economic applications, such as Young $(1993,1996)$, and Kandori, Mailath and Rob (1993). The basic idea here is to take, say, a standard replicator dynamic game-theoretic problem and convert it into a stochastic differential equation by adding 'mutation noise', i.e., a small given probability for an agent employing any one strategy to spontaneously change to any other strategy. For any level of noise this will lead to an asymptotic limiting distribution, which may be multimodal, reflecting multiple equilibria in the underlying game. These limiting distributions, in turn, can be shown to collapse to a single strategy in the limit as the noise goes to zero, the equilibrium strategy which requires the largest number of mutations to escape from, compared to the other possible equilibria. This strategy is then denoted the stochastically stable equilibrium

The attraction of this argument for game theoretists is as an answer to the so-called equilibrium selection problem. The fact that many interesting games lead to multiequilibria seems to be very unsettling for most game theoretists, since rationality of the actors is no longer sufficient to determine which outcome will obtain and thus is an inadequate guide to action. The argument from path dependence-that history and small events determine the long-term outcome-does not appear to be satisfying for the game theory camp. Stochastic stability, however, appears to be a way to recapture uniqueness of equilibria and thus solve the unsettling equilibrium selection problem. Unfortunately, there are problems here as well, since the assumption of a uniform and state-independent mutation process itself proves to be highly arbitrary, and on different assumptions any other result can be shown to obtain (cf. Bergin and Lipman 1996, and Kirman's chapter in this volume).

\section{Innovation}

${ }^{6}$ The question whether nuclear power technology and the standardization on light water reactors is an example of path dependence or not thus also partly hinges on whether the number of installations is really large enough for the mathematical argument to be credible. 
Until now all of the approaches we have examined were purely selectionist: all possible entities at time zero are already present in the population, no new ones are added, and the only possibility is that some will be eliminated and the relative shares of others will change. True evolution, of course, also involves the creation of novelty in real time via random mechanisms. Instead of a strategy space of low dimension and full support ${ }^{7}$, the modeling framework must be expanded to a more complicated space, high dimensional and/or effectively infinite, and only sparsely occupied.

A number of search spaces and landscapes have been proposed in the evolutionary literature. Directed graphs have been employed by Silverberg and Lehnert $(1994,1996)$ and Silverberg and Verspagen (1994, 1996), and Vega-Redondo (1994). Technologies are nodes on the graph (corresponding for example to fixed coefficient linear production functions) with the arrow representing technological succession. The directed graph structure allows for ordering, a notion of nominal technological distance, and the possibility of branching (or convergence). The classical Nelson and Winter model also uses fixed coefficient technologies, but as points randomly scattered in the Euclidian space of the (logs of) capital and labour productivities. A distance norm is imposed (the diamond metric) which measures how easily the randomly directed $R \& D$ search process can move the firm from one point to another. Similarly, Kwasnicki and Kwasnicka (1992) invokes a multidimensional contoured landscape over technological characteristics, the shape of the landscape being chosen arbitrarily but intended to reflect the possibility of multiple peaks separated by valleys. Kauffman has taken the possibility of representing the ruggedness of landscapes systemically further with his notion of the NK fitness model (Kauffman 1993, Kauffman and Macready 1995).

Silverberg and Verspagen $(1994,1996)$ also investigate evolution in a behavioral space of R\&D investment strategies complementary to the technological graph. Here, behavioral rules of thumb are parameterized by one or two real numbers for each firm, so that the strategies are actually a continuum with a fitness landscape induced by the selection dynamics of market competition and relative capital stock growth. And whereas the search algorithm in technology space is an $R \& D$ production function determining the probability of advancing to the next node on the directed graph, the genetic operators governing search in the behavioral space are borrowed from the evolutionary strategy literature (Schwefel 1995).

${ }^{7}$ In most of the evolutionary game theory literature being at the minimum level of two. 
Mutation is a local perturbation of existing parameter values drawn from a normal distribution, while recombination/imitation is the copying of part of the strategy string of a competitor $^{8}$. This is in contrast to the otherwise very similar operators employed in genetic algorithms (Holland 1975, Goldberg 1989) on discretely coded strings. There mutations are decidedly nonlocal. A simplified version of genetic algorithms using only successive one-point mutations in hill-climbing exercises is also the focus of Kauffman's work on NK fitness landscapes.

The computer-based modeling with artificially intelligent agents in complex interaction with each other has culminated in the notion of artificial worlds (Lane 1993). The idea here is to create a model populated with agents capable of adaptation rich enough for complex behaviour to emerge spontaneously over time instead of having the modeller specify a problem to be solved explicitly. Examples primarily in the biological domain can be found in Langton (1995) and in economics in particular in Epstein and Axtell (1996). Key concepts, which however still remain hard to formalize, are emergence and punctuated equilibrium, which seem to characterize generically the kinds of collective behavioral patterns generated by many of these models.

\section{Significant results for economics}

In the preceding I have examined the methodological components taken almost in isolation that have gone into the evolutionary modeling effort in the last few years, and that now offer themselves for assembly in new models. In this concluding section I would like to very briefly make reference to the literature in terms of significant results in specific areas of economic inquiry. Growth models with an evolutionary perspective are surveyed in Silverberg and Verspagen (1995c). Therefore, I will not attempt to reproduce that discussion here. Another area in which considerable progress has been achieved falls under the general heading of industry structure models. The first group deals with the size distribution question, which is expertly reviewed and expanded upon in Dosi, Marsili, Orsenigo, and Salvatore (1995). The second deals with industry life cycles and has been advanced both theoretically

${ }^{8} \mathrm{~A}$ further economically motivated modification is made so that the probability of imitation increases the less successful a firm is compared to the most dynamic firms. 
and empirically in particular by Klepper (1996a).

Finally, the evolutionary method has been applied with some success to a number of questions of economic behaviour. First, the work of Crawford (1991) has done much to elucidate from an evolutionary perspective the intriguing experimental results on coordination games obtained by van Huyck, Battalio, and Beil (1990). Second, the evolutionary game literature has been increasingly marshalled to say something about the origin of economic conventions (Young 1993, 1996). Third, the line of inquiry opened up by Axelrod (1984) employing the iterated Prisoner's Dilemma as a canonical tool for questions of cooperation has burgeoned in recent years. The arsenal of numerical and artificial intelligence tools has especially contributed to deepening this field of research, with extensions to spatially structured populations, error making, and the like.

In refutation of my original devil's advocate hypothesis I would advance the following theses. First, the toolbox of evolutionary modeling has now reached the stage of reasonable systematization and consistency, so that a coherent dialog between the disparate approaches is being facilitated and the taint of ad hocery is beginning to recede. Second, evolutionary models are gradually moving out of the sandbox of being interesting curiosities or toy alternatives to mainstream theorizing. They are acquiring theoretical status in their own right and are also beginning to yield their first dividends in terms of empirically testable results.

\section{References}

Alchian, A. A., 1951, "Uncertainty, Evolution, and Economic Theory", Journal of Political Economy, 58: 211-222.

Allen, P. M., 1975, "Darwinian Evolution and a Predator-Prey Ecology", Bulletin of Mathematical Biology, 37: 389-405.

Allen, P. M., 1976, "Evolution, Population Dynamics, and Stability", Proceedings of the National Academy of Sciences USA, 73: 665-669.

Amable, B., 1992, "Competition among Techniques in the Presence of Increasing Returns to Scale", Journal of Evolutionary Economics, 2: 147-158.

Andersen, E.S., 1994, Evolutionary Economics. Post-Schumpeterian Contributions, London: Pinter.

Arthur, W. B., 1994, Increasing Returns and Path Dependence in the Economy, Ann Arbor, MI: University of Michigan Press.

Arthur, W. B., Ermoliev, Y.M. and Kaniovski, Y.M., 1984, "Strong laws for a class of path-dependent urn processes", in Arkin, Shiryayev,and Wets, (eds), Proceedings of the International Conference on Stochastic Optimization, Kiev 1984, Berlin, Heidelberg, New York, Tokyo: Springer-Verlag.

Axelrod, R., 1984, The Evolution of Cooperation, New York: Basic Books. 
Bergin, J. and Lipman, B.L., 1996, "Evolution with State-Dependent Mutations", Econometrica, 64(4): 943-956.

Bruckner, E., Ebeling, W.,Jiménez Montaño, M. A. and Scharnhorst, A., 1996, "Nonlinear Stochastic Effects of Substitution - An Evolutionary Approach", Journal of Evolutionary Economics, 6: 1-30.

Cowan, R., 1991, "Tortoises and Hares: Choice among Technologies of Unknown Merit", Economic Journal, 101: 801-814.

Crawford, V. P., 1991, "An 'Evolutionary' Interpretation of Van Huyck, Battalio, and Beil's Experimental Results on Coordination", Games and Economic Behavior, 3: 25-59.

Dopfer, K., 1997 (forthcoming), The Evolutionary Principles of Economics, Cambridge: Cambridge University Press.

Dosi, G., Marsili, O.,Orsenigo, L.and Salvatore, R., 1995, "Learning, Market Selection and the Evolution of Industrial Structures", Small Business Economics, 7: 1-26.

Dosi, G. and Kaniovski, Y., 1994, "On "Badly Behaved" Dynamics. Some Applications of Generalized Urn Schemes to Technological Change", Journal of Evolutionary Economics, 4: 93-123.

Dosi, G. and Nelson, R.R., 1994, "An Introduction to Evolutionary Theories in Economics", Journal of Evolutionary Economics, 4: 153-172.

Durlauf, S.N., 1996, "Neightborhood Feedback, Endogenous Stratification, and Income Inequality", in Barnett, W.,Gandolf, G. and Hillinger, C., (eds), Dynamic Disequilibrium Modelling, Cambridge: Cambridge University Press.

Ebeling, W. and Feistel, R., 1982, Physik der Selbstorganisation und Evolution, Berlin: Akademie Verlag.

Englmann, F.C., 1988, "Technological Change and Increasing Returns", in Flaschel, P. and Krüger, M., (eds), Recent Approaches to Economic Dynamics, Frankfurt: Lang.

Englmann, F.C., 1992, "Innovation, Diffusion, Employment and Wage Policy", Journal of Evolutionary Economics, 2: 179-193.

Englmann, F.C., 1994, "A Schumpeterian Model of Endogenous Innovation and Growth", Journal of Evolutionary Economics, 4: 227-242.

Epstein, J.M. and Axtell, R., 1996, Growing Artificial Societies. Social Science from the Bottom Up, Washington, DC: Brookings Institution.

Fisher, R. A., 1930, The Genetical Theory of Natural Selection, Oxford: Clarendon Press.

Foster, D. and Young, P., 1990, "Stochastic Evolutionary Game Dynamics", Theoretical Population Biology, 38: 219-232.

Goldberg, D., 1989, Genetic Algorithms in Search, Optimization, and Machine Learning, Reading MA: Addison-Wesley.

Hammerstein, P. and Selten, R., 1994, "Evolutionary Game Theory", in Aumann, R. J. and Hart, S., (eds), Handbook of Game Theory with Economic Applications, Amsterdam: North Holland.

Henkin, G.M. and Polterovich, V.M., 1991, "Schumpeterian Dynamics as a Non-linear Wave Theory", Journal of Mathematical Economics, 20: 551-590.

Hodgson, G., 1993, Economics and Evolution: Bringing Back Life into Economics, Ann Arbor, MI: University of Michigan Press.

Hofbauer, J. and Sigmund, K., 1988, The Theory of Evolution and Dynamical Systems, Cambridge: Cambridge University Press.

Holland, J. H., 1975, Adaptation in Natural and Artificial Systems, Ann Arbor: University of Michigan Press. 
Iwai, K., 1984a, "Schumpeterian Dynamics. I: An Evolutionary Model of Innovation and Imitation ", Journal of Economic Behavior and Organization, 5: 159-90.

Iwai, K., 1984b, "Schumpeterian Dynamics. II: Technological Progress, Firm Growth and "Economic Selection"", Journal of Economic Behavior and Organization, 5: 321-51.

Jiménez Montaño, M. A. and Ebeling, W., 1980, "A Stochastic Evolutionary Model of Technological Change", Collective Phenomena, 3: 107-114.

Kandori, M., 1996, "Evolutionary Game Theory in Economics", Tokyo, Japan: Research Institute for the Japanese Economy, University of Tokyo, Discussion Paper.

Kandori, M., Mailath, G.J. and Rob, R., 1993, "Learning, Mutations, and Long Run Equilibrium in Games", Econometrica, 61(1): 29-56.

Kauffman, S.A., 1993, The Origins of Order. Self-Organization and Selection in Evolution, New York and Oxford: Oxford University Press.

Kauffman, S. and Macready, W., 1995, "Technological Evolution and Adaptive Organizations", Santa Fe, NM: Santa Fe Institute Working Paper 95-02-008.

Klepper, S., 1996, "Exit, Entry, Growth, and Innovation over the Product Life Cycle", American Economic Review, 86(3): 562-583.

Kwasnicki, W., 1996a, Knowledge, Innovation and Economy. An Evolutionary Exploration, Aldsershot: Edward Elgar.

Kwasnicki, W., 1996b, "Technological Development: An Evolutionary Model and Case Study", Technological Forecasting and Social Change, 52: 31-57.

Kwasnicki, W. and Kwasnicka, H., 1992, "Market, Innovation, Competition: An Evolutionary Model of Industrial Dynamics", Journal of Economic Behavior and Organization, 19: 343-368.

Lane, D.A., 1993, "Artificial Worlds and Economics. Parts 1 and 2", Journal of Evolutionary Economics, 3(2\&3): 89-108, 177-197.

Langton, C.G., (ed.) 1995, Artificial Life. An Overview, Cambridge, MA: MIT Press.

Liebowitz, S. J. and Margolis, S.E., 1990, "The Fable of the Keys", Journal of Law and Economics, 22: 1-26.

Liebowitz, S. J. and Margolis, S.E., 1994, "Network Externality: An Uncommon Tragedy", Journal of Economic Perspectives, 8(2): 133-150.

Liebowitz, S. J. and Margolis, S.E., 1995, "Path Dependence, Lock-In, and History", Journal of Law, Economics, \& Organization, 11(1): 205-226.

Maynard Smith, J., 1982, Evolutionary Game Theory, Cambridge: Cambridge University Press.

Metcalfe, J. S., 1988, "The Diffusion of Innovation: An Interpretative Survey", in G. Dosi et al., (eds), Technical Change and Economic Theory, London: Pinter.

Metcalfe, J. S., 1994, "Competition, Fisher's Principle and Increasing Returns in the Selection Process", Journal of Evolutionary Economics, 4: 327-346.

Nelson, R.R., 1995, "Recent Evolutionary Theorizing About Economic Change", Journal of Economic Literature, 33: 48-90.

Nelson, R. R. and Winter, S. G., 1982, An Evolutionary Theory of Economic Change, Cambridge MA: The Belknap Press of Harvard University Press.

Orlean, A., 1995, "Bayesian Interactions and Collective Dynamics of Opinions: Herd Behavior and Mimetic Contagion", Journal of Economic Behavior and Organization, 28: 257-274.

Saviotti, P. P. and Mani, G. S., 1995, "Competition, Variety and Technological Evolution: A Replicator Dynamics Model", Journal of Evolutionary Economics, 5: 369-392. 
Saviotti, P. P. and Metcalfe, J. S., (eds) 1991, Evolutionary Theories of Economic and Technological Change: Present Status and Future Prospects,

Schlag, K.H., 1994, "Why Imitate, and If So, How?", University of Bonn: Discussion Paper.

Schwefel, H. P., 1995, Evolution and Optimum Seeking, New York: Wiley.

Sigmund, K., 1986, "A Survey of Replicator Equations", in J.L. Casti and A. Karlqvist, (eds), Complexity, Language and Life: Mathematical Approaches, Berlin, Heidelberg, New York and Tokyo: Springer-Verlag.

Silverberg, G., 1984, "Embodied Technical Progress in a Dynamic Economic Model: the Self-Organization Paradigm", in Goodwin, R., Krüger, M. and Vercelli, A., (eds), Nonlinear Models of Fluctuating Growth,: 192-208 Berlin-Heidelberg-New York: Springer Verlag.

Silverberg, G., 1988, "Modelling economic dynamics and technical change: mathematical approaches to self-organisation and evolution", in Dosi, G.,Freeman, C., Nelson, R., Silverberg, G. and Soete, L., (eds), Technical Change and Economic Theory, London: Pinter.

Silverberg, G., Dosi, G. and Orsenigo, L., 1988, "Innovation, Diversity and Diffusion: A Self-Organisation Model", Economic Journal, 98: 1032-54.

Silverberg, G. and Lehnert, D., 1994, "Growth Fluctuations in an Evolutionary Model of Creative Destruction", in Silverberg, G. and Soete, L., (eds), The Economics of Growth and Technical Change: Technologies, Nations, Agents, Aldershot: Edward Elgar.

Silverberg, G. and Lehnert, D., 1996, "Evolutionary Chaos: Growth Fluctuations in a Schumpeterian Model of Creative Destruction", in Barnett, W. A., Kirman, A. and Salmon, M., (eds), Nonlinear Dynamics in Economics, Cambridge: Cambridge University Press.

Silverberg, G. and Verspagen, B., 1994, "Learning, Innovation and Economic Growth: A Long-Run Model of Industrial Dynamics", Industrial and Corporate Change, 3: 199-223.

Silverberg, G. and Verspagen, B., 1995, "Evolutionary Theorizing on Economic Growth", forthcoming in Dopfer, K. (ed.), The Evolutionary Principles of Economics, Cambridge: Cambridge University Press (also available as IIASA and MERIT Workings Papers WP-95-76 and 2/95-017).

Silverberg, G. and Verspagen, B., 1996, "From the Artificial to the Endogenous: Modelling Evolutionary Adaptation and Economic Growth", in Helmstädter, E. and Perlman, M., (eds), Behavorial Norms, Technological Progress and Economic Dynamics: Studies in Schumpeterian Economics, Ann Arbor, MI: University of Michigan Press.

Vega-Redondo, F., 1996, Evolution in Games: Theory and Economic Applications, Oxford: Oxford University Press.

Weibull, J., 1995, Evolutionary Game Theory, Cambridge, MA: MIT Press.

Weidlich, W. and Braun, M., 1992, "The Master Equation Approach to Nonlinear Economics", Journal of Evolutionary Economics, 2: 233-265.

Weidlich, W. and Haag, G., 1983, Concepts and Models of a Quantitative Sociology, Berlin: Springer-Verlag.

Weisbuch, G., Kirman, A.P. and Herreiner, D., 1996, "Market Organisation", GREQAM, Marseille: Working Paper 96A20.

Witt, U., 1994, "The Theory of Societal Evolution - Hayek's Unfinished Legacy", in Birner, J. and van Zijp, R., (eds), Hayek, Co-ordination and Evolution, London: Routledge.

Young, H. P., 1993, "The Evolution of Conventions", Econometrica, 61(1): 57-84. 
Young, H. P., 1996, "The Economics of Convention", Journal of Economic Perspectives, 10(2): 105-122.

van Huyck, J., Battalio, R. and Beil, R., 1990, "Tacit Coordination Games, Strategic Uncertainty, and Coordination Failure", American Economic Review, 80: 234-248. 